\title{
The Work-Study Experience Of Indigenous Undergraduates In Taiwan
}

\author{
Shan-Hua Chen, National Chiayi University, Taiwan
}

\begin{abstract}
Due to the large number of universities in Taiwan and the increased availability of scholarships for disadvantaged students, the number of college students from indigenous families has been on the rise in recent years. However, many indigenous students still find it necessary to work parttime. In this study, indigenous students were interviewed to determine how they choose part-time jobs and the influence such work has on their grades, health, and careers. Based on the results, suggestions are provided for improving the work-study experience of indigenous students.
\end{abstract}

Keywords: Indigenous Students; Higher Education; Work-Study

\section{INTRODUCTION}

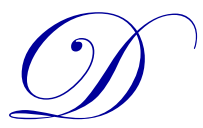

ue to increasing tuition costs, diminishing family support, and changing lifestyles, these days most college students have either part-time or full-time jobs (Moreau \& Leathwood, 2006; Beerkens, Magi, \& Lill, 2011). Through the 2011 American Community Survey (ACS), 45\% of college students have full-time jobs and $85 \%$ work part-time (Perna, 2010). Compared with the statistics from a decade earlier, more students now have part-time jobs and also work more hours (Beerkens, Magi, \& Lill, 2011).

The situation in Taiwan is similar to that in other developed countries. For instance, Chen (2007) found that the proportion of undergraduates with a part-time job has been steadily increasing and that many "full-time students" actually spend more time at work than at school. While there are government scholarships available for the increasing number of indigenous university students, they are rather limited in number and the amount awarded. As a result, many indigenous students from disadvantaged families don't receive scholarships, most of whom end up taking a part-time job in order to continue their studies.

Without a doubt, a student's work experience has a major influence on his or her academic success and career development, yet little research has been done in this area, especially when it comes to indigenous students. In one of the few related studies carried out in Taiwan, Wang and Chen (2013) focused on the work preferences of indigenous students and found that most indigenous students tend to work off campus. It was also found that their main reason for working was economic necessity and that they gave less importance to such benefits as expanding their social network and increasing their knowledge and skills.

While institutions of higher education in Taiwan do help their students find part-time work, they need to do more to assist indigenous students find meaningful and safe work. The aims of the present study were: 1) to determine the main reasons why indigenous students in Taiwan take part-time jobs, 2) to determine how they choose their jobs and what they learn from their work, 3) to evaluate the government assistance currently provided to indigenous university students, and 4) to examine the influence indigenous culture has on these issues. The results can be used by universities to improve the job assistance they provide to indigenous students.

\section{LITERATURE REVIEW}

Improving the overall economic conditions of indigenous people requires long-term investment in helping them gain access to higher education (Tang, 2002). For a long time, relatively few indigenous people in Taiwan received higher education. However, due to the expansion of higher education and increasing government assistance 
for aboriginals, the number of indigenous university students has steadily increased in recent years. From 2005 to 2009 , the proportion of indigenous college students increased from $1.01 \%$ to $1.33 \%$. However, about $34 \%$ of indigenous college students attend private vocational colleges which tend to provide a lower quality of education (Chen \& Ma, 2007).

Most indigenous college students come from poor families and have fathers who work as laborers. About one-quarter of indigenous college students receive student loans, while only $7 \%$ to $10 \%$ receive scholarships that cover all their expenses, and about $60 \%$ of indigenous college students are supported by their parents or relatives (Chen \& Ma, 2007). With figures like these, it comes as no surprise that many indigenous college students depend on student loans and part-time jobs to support themselves. To be sure, the scholarships provided by the various government departments also help indigenous students a lot. The Higher Education Database indicates that 29.6\% of indigenous students receive a scholarship sufficient to pay their tuition and fees. The proportion of overseas Chinese students (ethnic Chinese who are not citizens of the ROC or PRC) receiving the same level of assistance is only $15.5 \%$; for other students, the figure is only $5.4 \%$. Despite the considerable amount of government assistance, most indigenous students still have difficulty paying their tuition and living expenses (Chen \& Ma, 2007).

\section{Previous Research on Work-Study Students}

In this paper "work-study" refers to a student who is engaging in paid employment on or off campus, either while school is in session or during summer and winter vacations. The appropriateness of college students having part-time jobs has been the subject of a fierce debate. On the one hand, critics of work-study argue that students who engage in part-time employment sell themselves short and don't make the most of the precious time they have at college (Liberty Times, 2010). On the other hand, many work-study students claim that they gain valuable experience from their part-time work. The Council of Labor Affairs reports in 2006 that $40.4 \%$ of students engaged in part-time employment. The same report also states that $42.9 \%$ of female students work part-time, compared to $37.9 \%$ of male students; the ratio of students at private schools engaging in part-time work was $43.2 \%$, as compared to $35.3 \%$ at public schools; and that comparatively more sophomores $(45.0 \%)$ and juniors $(46.7 \%)$ have part-time jobs (Council of Labor Affairs, 2006).

By comparison, in advanced countries the proportion work-study students is higher than in Taiwan. For example, in the US, about $74 \%$ of college students have part-time jobs, $20 \%$ of whom work more than 35 hours per week. Moreover, about $63 \%$ of work-study students rely on their wages to help pay for their education (King \& Bannon, 2002). As for the percentage of indigenous work-study students in Taiwan, no surveys have been previously carried out; however, in light of recent social changes and the increasing number of aboriginals enrolling at universities, it would be expected that the numbers are on the rise.

Wang and Chen (2013) found that for $79.3 \%$ of indigenous students in Taiwan engaging in work-study mainly do so to make money. Huang and Lin (2010) assert that part-time employment is likely to teach young people to be diligent, responsible, self-confident, adaptable, self-disciplined, and trustworthy. It has also been found that work-study helps students develop skills, understand the relationship between theory and practice, and learn how to run a business (Chen, 2007; Lin \& Wang, 1992). Part-time employment can also give students valuable insights into the job market before graduating (Cheng \& Alcántara, 2007) enhance their sense of social responsibility (Collins, 2002); provide opportunities to interact with others, build their social networks, and enhance their social skills (Huang \& Lin, 2010; Cheng \& Alcántara, 2007; Lin \& Wang, 1992); and learn about the real world (Curtis \& Shani, 2002).

Whether or not work-study experience helps recent graduates in their job search largely depends on how related it was to their studies. Ford and Bosworth (1995) found that the work-study experience of most students has little relevance to their major. In a study published by Taiwan's Council of Labor Affairs (2006), only $12.4 \%$ of the participating work-study students felt that their work experience was highly related to their studies, while $68.1 \%$ felt that their work experience was completely unrelated to their studies. However, in the same study, $81.6 \%$ of the students indicated that their work experience was helpful to their future career development, while only $16.9 \%$ felt that their work experience had not been beneficial to their career development. Callender and Wilkinson (2003) found that on-campus part-time work as a research or administrative assistant does tend to increase a student's 
professional skills but that disadvantaged students find it more difficult to get such jobs and thus tend to opt for manual labor.

Research has shown that working more than 15 hours per week at a job that is not related to one's major has a negative influence on academic performance (Hay, Evans, \& Lindsay, 1970; Ma \& Wooster, 1979). It has also been found that many students think that taking a part-time job has a negative influence on grades and attendance (Curtis \& Shani, 2002). Further, work-study students may have to spend more time to complete their degree (Hakkinen, 2006). As for the situation in Taiwan, research has found that students who don't take part-time jobs tend to be better prepared for class and are also more like to actively participate in class activities. However, it has also been found that work-study students are less likely to skip classes (Chen, 2007).

Although some (Beerkens, Magi, \& Lill, 2011; Royal, 2001) have found that work-study has little influence on grades, others (Salamonson, Everett, Koch, Andrew, \& Davidson, 2012) have found that it has a negative influence. One study (Noel-Levitz, 2010) found that the academic performance of students who work a moderate amount of hours is better than that of those who don't have a part-time job. It has also been found that college students who work in a high-quality environment tend to be more mature and get better grades (Healy, O'Shea, \& Crook, 1985).

Research has also found a correlation between work-study and increasing use of alcohol, cigarettes, and medicine; a lack of exercise; and a lower rate of attendance (Mortimer, Finch, Ryu, Shanahan, \& Call, 1996; Laberge et al., 2011). Work-study involving strenuous labor may cause acute or even chronic fatigue, something which tends to result in poor academic performance. Extreme chronic fatigue may eventually give rise to cognitive or emotional disorders (Carskadon, 2002; Dahl \& Lewin, 2002; Laberge et al., 2011). Thus, although work-study may be beneficial in various ways, it can also have a negative influence on one's physical and mental health (Smith, Gorski, Hagmann, \& Qakley, 2002). In comparison with adults, young people entering a new working environment have less cognitive ability and physical coordination, and thus face more risks (Miller, Handelman, \& Lewis, 2007).

Cheng and Alcántara (2007) warn that in addition to poor grades, work-study can also greatly reduce the time one has for leisure, sleep, and socializing with classmates. Moreau and Leathwood (2006) also found that work-study students tend to socialize less with their classmates. However, work-study provides students with the opportunity to make new friends at the workplace.

\section{METHODOLOGY}

\section{Research Site and Participants}

The participants consisted of indigenous students at a national university in southern Taiwan. Of the approximately 12,000 students enrolled at this above-average university at the time of the study, 144 were members of one of the dozen or so ethnic groups officially recognized as indigenous to Taiwan (i.e., non-Han Chinese). The university has a center for providing indigenous students with counseling and also helps students apply for scholarships offered by the Council of Indigenous Peoples. Students who receive these scholarships are required to enroll in the school's work-study program and typically work in one of the school's administrative offices for 48 to 60 hours per semester (Council of Indigenous peoples, 2008). Their hourly wages are about twice the average amount received by other students for on-campus work and can be three times the amount received for off-campus work.

Interviews were conducted with ten indigenous students who were either working on or off campus. Because of their limited work experience, freshmen were not included. Each interview ran for about one hour. The background information of the participants is shown in Table 1. 
Table 1: Background Information of the Participants

\begin{tabular}{|c|c|c|c|}
\hline Student & Gender & Year & Work Experience (Months) \\
\hline S1 & Male & Junior & School Library (5) \\
\hline S2 & Male & Sophomore & $\begin{array}{c}\text { Cram School (3) } \\
\text { Bottled Water Delivery (3) }\end{array}$ \\
\hline S3 & Female & Senior & Research Assistant (36) \\
\hline S4 & Female & Senior & Research Assistant (36) \\
\hline S5 & Female & Senior & $\begin{array}{c}\text { Restaurant (3) } \\
\text { Tutor (2) }\end{array}$ \\
\hline S6 & Male & Senior & Dental Assistant (12) \\
\hline S7 & Male & Sophomore & $\begin{array}{c}\text { School Library (5) } \\
\text { Restaurant (4) }\end{array}$ \\
\hline S8 & Female & Junior & $\begin{array}{c}\text { Restaurant (12) } \\
\text { Hotel (School Vacations) }\end{array}$ \\
\hline S9 & Male & Sophomore & Student Affairs Office, School Library, Tutor (36) \\
\hline
\end{tabular}

\section{Procedures}

Semi-structured interviews were the main method of data collection for this qualitative study. The role of the interviewer was to listen, observe, and interpret without bias or judgment (Brenner, 2006) in expectation that such an approach would encourage the interviewees to freely and accurately express their experiences and views. The interviews focused on the participants' reasons for taking part-time employment, the problems they face at work, and the influence their ethnic identity has had on their choice of work. After receiving the participant's consent, each interview was recorded. Soon after concluding, each interview was transcribed and the contents were checked for consistency with notes written down during the interview. The interview data was then sifted, encoded, and categorized to facilitate analysis. For coding purposes, each quotation will be added to the interview date at the end. For example, if the quotation's interview was done on October 20, 2013, then (Oct. 20, 2013) will be added at the end. Self-reflection was used to reduce personal bias. If there were any doubts concerning the interview data, a follow-up interview was conducted either in person or by phone.

\section{Research Ethics}

The two ethical principles applied in this study were "informed consent" and "participant safety." In light of the former, the participants were informed of the purpose, risks, and voluntary nature of participation in the study. In light of the latter, all reasonable precautions were made to insure that the participants would not be exposed to harm due to their participation. Finally, the participants were informed that they would remain anonymous.

\section{RESULTS}

\section{Reasons for Engaging in Work-Study}

Many indigenous students are from low-income families and experience financial difficulties. Thus, their parents often expect that they will cover their own expenses by applying for scholarships and taking part-time work. This is especially the case if the family has several school-age children. However, indigenous families in a better economic situation generally prefer that their children not engage in work-study in the belief that doing so would have a negative effect on their academic achievement. Some pertinent excerpts from the interviews are as follows:

Q: $\quad$ What is your mother's view of work-study?

S1: $\quad$ She thought that I shouldn't neglect my studies just to earn a little money, since doing so might make it more difficult to make good money in the future. (October 08, 2013)

S9: My parents think it's okay to work during school holidays, but not during the semester. They are probably worried that having a part-time job would not be good for my schoolwork. They hope I can work part-time to earn some pocket money and ease the burden on my family. (October 24, 2013) 
S8: $\quad$ In my family there are four children and only my younger brother and I are in school. My parents basically said, "However much you need, you'll have to earn it by yourself." As a result, I realize how hard it is to make money. (October 30, 2013)

S6: $\quad$ My parents want me to pay more attention to my schoolwork since they worked really hard to help me go to college. In spite of this, I still insist on working part-time. After I started my part-time job, I think they felt much relieved to see that I was growing up. (October 24, 2013)

One participant's father is a teacher and was acquainted with one of the student's professors; this made it easier for this student to get work as a research assistant.

Q: $\quad$ How did you get your job?

S3: The professor I work for once cooperated with the school at which my father works and they became friends. When this professor needed a research assistant, I got the job.

Q: So, your father got you the job?

S3: $\quad$ Yes. I don't care much about the money. I mean, I don’t really need this job. (October 17, 2013)

\section{Types of Work}

Like most undergraduates, most indigenous students work part-time during winter and summer vacations to help pay their tuition and other expenses. Most work off campus. Many find their jobs on employment websites, but most rely on referrals from relatives and friends.

S7: $\quad$ My uncle is a dentist and he needed to hire more people for the evening shift. My school is not far from his office, so I started working there to help him out and also to make some money. (October 26, 2013)

S9: I got a job as a room attendant because my elder sister worked at the front desk of the hotel. I had applied earlier to that hotel, but I didn't get hired because I didn't have any experience. However, when the hotel was short-handed, they gave me the job based on my sister's recommendation. I worked hard after getting the job and now I will work there during my summer and winter vacations. (October 24, 2013)

As for off-campus work, when school is in session, the options are limited to the areas nearby the school. Most students prefer jobs related to their studies. For example, education students commonly apply for jobs in cram schools, and those who major in physical education apply for jobs as training coaches. "If I simply want to work part-time, it would be easy enough to get a job at a store. But in order to get more out of a part-time job than just money, I'd like to find a job which is related to my studies," one student said. Still, many students have to settle for part-time jobs which bear little or no relation to what they are studying. "I do the same thing for eight hours. It's tiring and not very useful for my future career," one student said about his experience working in a factory.

S9: Being a history major with average grades, I am not sure what I can do in the future. Perhaps I will be a tutor. If I want to get a job which is associated with my major, I need to have better grades.

Q: Do you mean you won't study further?

S9: $\quad$ I guess so. (October 24, 2013)

During the semester, most indigenous students who need a part-time job hope to work on campus, but few actually do. Occasionally the school conducts a research project concerned with indigenous themes for which aboriginal students are hired for such tasks as designing teaching materials and general assistance. However, such opportunities are rare.

S3, S4, S5: It's basically developing teaching materials. Because we will become teachers in elementary schools, we have to learn how to design teaching materials on our own and integrate these things into indigenous culture. (October 17, 2013) 


\section{The Benefits and Drawbacks of Work Study}

Most indigenous work-study students work off campus. Although the pay is relatively low and usually unrelated to their studies, they do gain valuable experience in such areas as dealing with people. Most students believe that working part-time off campus is a good way to gain some experience and expand their social network.

S6: Working in a catering business you meet people of all ages and from all walks of life; teaching in a cram school you only work with kids. (October 24, 2013)

Q: What have you learned from your part-time job?

S9: I've learned how to get along with strangers and improved my communication skills. This is important when there is a problem with customers or the boss.

Q: Have you ever been criticized by your manager?

S9: $\quad$ Yes, I have. He said that a full-time employee should be more efficient. (October 24, 2013)

Q: $\quad$ What do you think, S2?

S2: Working off-campus you learn how society operates. When I worked part-time at my father's company, I met various people and learned a lot about the relationship between employers and employees; that is something you don't learn at school. (October 08, 2013)

However, work-study can also have some bad effects on students, such as stress and health problems caused by overwork. Some indicated that excessive pressure at work affected their extracurricular activities, friendships, and academic performance.

S9: At my first job, I had to work from noon until half past ten at night without much of a break. I tried energy drinks, but it didn't help. This job had a bad impact on my concentration and health. Perhaps I didn't use my time properly. I should have taken a proper break, but instead I would turn on my mobile phone or watch TV. (October 24, 2013)

Q: $\quad$ Do you have any work in addition to being a research assistant?

S3: $\quad$ Actually, I only had to go there for two hours a week, but I had to spend more time after work. It required more time than I expected and I became irritable with my friends. Undoubtedly, I didn't have enough time for my school work and campus organizations.

S5: If I didn't do well, I would feel upset and stressed. Sometimes I suffered from insomnia. Since I didn't and couldn't reach the goal the professor set, I was under a lot of pressure. (October 17, 2013)

However, students who learn to manage their time properly gain more benefits from working part-time.

Q: $\quad$ You just said that working part-time didn’t affect your academic performance. How do you balance the two?

S7: $\quad$ Since I finished my work early, I had lots of time to study. Besides, I didn't need to work on weekends. (October 26, 2013)

S1: The advantage is that working part-time made me complete my school work in advance. Sometimes I had to refuse social invitations the night before going to my part-time job since staying up late would not be good for my job performance. (October 08, 2013) 


\section{Scholarships for Indigenous Students}

There are few part-time jobs on campus and the positions which offer students the opportunity to increase their professional knowledge and skills are usually taken by non-indigenous students. Some indigenous students don't even apply because they feel that they are unqualified for such jobs. Other participants reported that the job descriptions are not very clear. While some indigenous students are content to be paid well, no matter what the work, many would rather not work at menial jobs unrelated to their studies.

S6: I applied and was assigned to the Office of Student Affairs; I didn't have any choice. . . According to the current regulations, scholarships are awarded according to your grades.

Q: What benefits did you gain by receiving the scholarship?

S6: $\quad$ Maybe it helped me to lighten the economic burden of my family, but that's about all. As for the work, I just swept the floor, but I learned nothing. (October 24, 2013)

S1: In fact, most students are assigned custodial duties, largely because the results are announced late, after every department already has enough personnel. When indigenous students get a part-time job on campus, they usually don't have much to do; they just try to look busy, and then collect their pay.

Q: $\quad$ So, what's your opinion about indigenous students taking part-time jobs at school?

S1: I think the work they do is not essential. I dusted the library and I got paid twice as much per hour as nonindigenous students. I feel it is not fair. (October 08, 2013)

Q: Have you applied for a part-time job through the indigenous scholarship program?

S4: $\quad$ No. I don't want to.

S2: Why not?

S4: $\quad$ Because I don't want to spend my time like that. You just go to the library to lock the door or something like that, but you don't learn anything. (October 17, 2013)

According to the participants, even though they are paid well for on-campus work, many feel that their work is neither necessary nor related to their studies. Some are uncomfortable with the idea of getting paid so well for doing such an easy job and are not happy about the resentment this generates amongst non-indigenous students.

\section{The Relationship between Work-Study and Indigenous Culture}

When applying for jobs, some indigenous students tend to not reveal their ethnicity unless the employer seems well disposed to aboriginals or there are many indigenous people at the workplace.

S6: When I first started working there, I didn't tell anyone that I'm an aboriginal.

Q: $\quad$ Why not?

S8: $\quad$ Because most people have negative stereotypes about aboriginals.

Q: What are the stereotypes?

S8: $\quad$ Some people think we are only good at heavy labor.

S6: Someone thinks that indigenous people should do all the hard work ... It seems that as long as you are an aboriginal, you won't get a good salary. Some aboriginals receive benefits from the government, such as scholarships and preferential admission to university, but some non-aboriginals resent that. (October 24, 2013)

S8: I never reveal my indigenous identity when I go for an interview because if I do, I might get the job simply by virtue of my ethnic identity. I think it would be better to get the job based on my ability. (October 30, 2013) 
Although multicultural education has been promoted in Taiwan for some years now, ethnic stereotypes remain deeply entrenched. As a result, some indigenous students feel that they are at a disadvantage while looking for a job.

\section{DISCUSSION AND CONCLUSION}

Although larger numbers of indigenous students are gaining admission to university, many need to take part-time jobs to pay their tuition and living expenses. The results of this study indicate that most indigenous workstudy students work off campus and that most work mainly due to economic necessity. These findings are similar to those of Wang and Chen (2013). It was also found that the part-time work performed by most indigenous students has little relationship to their studies, similar to the findings of Ford and Bosworth (1995).

Further, most indigenous students find their jobs through recommendations from relatives and friends. Indigenous students who receive a work-study scholarship are usually assigned to such non-essential jobs as cleaning; although the pay is good, many students feel that they don't learn much from such jobs. This finding is similar to that of Callender and Wilkinson (2003) who found that work-study students from disadvantaged backgrounds usually perform physical labor.

However, the results also indicate that most of the participants in this study would agree with Huang and Lin's (2010) assertion that taking a part-time job makes students more diligent, responsible, self-confident, and adaptable. Yet, such work-study opportunities are very limited for indigenous students. Probably the main opportunity for performing meaningful work is when they are hired to assist in a project relating to indigenous culture, but these are not common. Thus, most of the participants would agree with Curtis and Shani's (2002) claim that the most beneficial part of work-study are the opportunities it provides for expanding one's social network.

As for the influence of work-study on their academic studies, none of the participants spent a large amount of time at work. However, the participant who worked as a research assistant was more confident about his future career and was also more willing to spend more time at work. This supports the findings of Healy, O'Shea, and Crook (1985) who claim that working in a high quality environment fosters personal and professional maturity. The main negative effects of taking a part-time job mentioned by the participants were reduced time for clubs, socializing, and leisure; increased stress; and lack of sleep.

This study also found that many indigenous students lack confidence to compete with non-indigenous students for on-campus jobs. Also, some indigenous students tend to conceal their ethnic identity so as to avoid being stereotyped. Finally, it was found that some aboriginal students have misgivings about receiving preferential financial aid. Although they may need the money, some feel like they didn't really earn it by doing a necessary and respected job.

Access to higher education is widely understood to be essential to the economic advancement of minority communities. However, despite a steady increase in recent years, the number of Taiwanese aboriginals attending university is still quite limited. Although the government does provide some assistance in the form of scholarships and preferential admissions for indigenous students, much more remains to be done. The results of this study suggest that the work-study program for aboriginal students is one area which has much room for improvement.

\section{LIMITATIONS AND RECOMMENDATIONS}

This study found that although indigenous work-study students receive a good wage, they are usually assigned to jobs that have little relation to their studies and thus don't gain much benefit in terms of career development. Therefore, it is suggested that indigenous student centers should pay more attention to assisting students in finding jobs as teaching or research assistants. In addition, related school departments should organize and promote activities and programs in indigenous areas and find ways to get indigenous students involved. This may also help to alleviate the shortage of skilled professionals in aboriginal areas. 
As for the limitations of this study, due to the limited sample, the types of work-study jobs included in this study were fairly small and the results may not be highly representative of other schools in other parts of Taiwan. For example, larger cities offer a greater diversity of work-study opportunities. Other important factors influencing work-study experience include whether or not the school has an indigenous student center, the proportion of indigenous students enrolled at the school, and the quality of interaction between indigenous and non-indigenous people in a particular locality. These are issues that need to be taken up in follow-up research.

\section{AUTHOR INFORMATION}

Chen Shan-Hua is an associate professor in the Graduate Institute of Educational Administration and Policy Development at National Chiayi University in Taiwan. She teaches courses in the sociology of education, multicultural education, teaching methodology, and qualitative research methods. While her early research addressed the educational experience of working-class students in Taiwan, her current research interests focus on indigenous students. Although not an aboriginal, she specializes in the education of indigenous and disadvantaged students. She has received several project grants and awards from the National Science Council of Taiwan. Her research papers on indigenous and multicultural education have been published in related journals. E-mail: shanhua@mail.ncyu.edu.tw

\section{REFERENCES}

1. Beerkens, M., Magi, E., \& Lill, L. (2011). University studies as a side job: Causes and consequences of massive student employment in Estonia. Higher Education, 61, 679-692.

2. Callender, C., \& Wilkinson, D. (2003). $2002 / 03$ student income and expenditure survey: Students' income, expenditure and debt in 2002/ 03 and changes since 1998/99. London: Department for Education and Skills. Retrieved December 2, 2012 from http://niesr.ac.uk/sites/default/files/publications/021007_121950.pdf

3. Carskadon, M. A. (2002). Adolescent sleep patterns: Biological, social and psychological influences. Cambridge, United Kingdom: Cambridge University Press.

4. Chen, P.-Y., \& Ma, G.-S. (2007). Indigenous college students schooling status, economic burden, and desire to continue studying. Taiwan Higher Education Database, 7, 3-34.

5. Chen, S.-J. (2007). The phenomenon of Taiwanese college students taking part-time jobs. Taiwan Higher Education Database, 11, 8-22.

6. Cheng, D. X., \& Alcántara, L. (2007). Assessing working student's college experiences: A grounded theory approach. Assessment and Evaluation in Higher Education, 32(3), 301-311.

7. Collins, T. L. (2002). The effect of a summer camp work experience program on young adolescents. (Unpublished doctoral dissertation). The Claremont Graduate University, Claremont, CA.

8. Council of Indigenous Peoples (2008). Grant implementation guidelines of Council of Indigenous Peoples Indigenous college and university students. Retrieved Oct. 2, 2013 from http://law.apc.gov.tw/LawContentDetails.aspx?id=FL029068\&KeyWordHL=\&StyleType=1

9. Council of Labor Affairs (2006). Survey report of college students' part-time jobs. Retrieved Dec. 2, 2012 from http://statdb.cla.gov.tw/html/svy95/9507menu.htm

10. Curtis, S., \& Shani, N. (2002). The effect of taking paid employment during term-time on students' academic studies. Journal of Further and Higher Education, 26(2), 129-138.

11. Dahl, R. E., \& Lewin, D. S. (2002). Pathways to adolescent health sleep regulation and behavior. Journal of Adolescent Health, 31, 175-84.

12. Department of statistics (MOE) (2009). The analysis of indigenous students and the gender of the teachers. Retrieved Nov. 2, 2013 from http://www.edu.tw/files/site_content/B0013/98native-gender.pdf

13. Ford, J., \& Bosworth, D. (1995). Part-time work and full-time higher education. Studies in Higher Education, 20(2), 187-202.

14. Hakkinen, I. (2006). Working while enrolled in a university: Does it pay? Labour Economics, 13, 167-189.

15. Hay, J. E., Evans, K., \& Lindsay, C. A. (1970). Student part-time job: Relevant or nonrelevant. Vocational Guidance Quarterly, 19, 113-118.

16. Healy, C. C., O'Shea, D., \& Crook, R. H. (1985). Relation of career attitudes to age and progress during college. Journal of Counseling Psychology, 32, 239-244. 
17. Huang, Y.-C., \& Lin, S.-H. (2010). Relationship between part-time work or practical training, and work value of college students in central Taiwan. Taiwan Counseling Quarterly, 2(2), 36-57.

18. King, T., \& Bannon, E. (2002). At what cost? The price that working students pay for a college education. The State PIRGs' higher education project. Washington DC: United States Public Interest Research Group.

19. Laberge, L., Ledoux, E., Auclair, M., Thuilier, D., Gaudreault, M., Gaudreault, M., Veillette, S., \& Perron, M. (2011). Risk factors for work-related fatigue in students with school-year employment. Journal of Adolescent Health, 48, 289-294.

20. Lin, B.-J., \& Wang, H.-C. (1992). A study of part-time University students. Research Report of National Youth Commission, Executive Yuan.

21. Ma, L., \& Wooster, R. A. (1979). The effect of unemployment on the college student's academic performance. College Student Journal, 13, 12-20.

22. Metcalf, H. (2003). Increasing inequality in higher education: The role of term-time working. Oxford Review of Education, 29(3), 315-329.

23. Miller, M. E., Handelman, E., \& Lewis, C. (2007). Protecting young workers: Coordinated strategies help to raise safety awareness. Professional Safety, 52(6), 38-45.

24. Moreau, M., \& Leathwood, C. (2006). Balancing paid work and studies: Working (-class) students in higher education. Studies in Higher Education, 31(1), 23-42.

25. Mortimer, J. T., Finch, M. D., Ryu, S., et al. (1996) The effects of work intensity on adolescent mental health, achievement, and behavioral adjustment: New evidence from a prospective study. Child Development, 67, 1243-61.

26. Noel-Levitz White Paper. (2010). White paper-enhancing student success by treating "student jobs" as "real jobs". Retrieved December 2, 2012 from https://www.noellevitz.com/documents/shared/Papers_and_Research/2010/StudentEmployeeSuccess.pdf

27. Perna, L. W. (2010). Understanding the working college student. Academe, 96(4), 30-33.

28. Royal, M. (2001). Methods of job search: How university students search for part-time jobs. (Unpublished master's thesis). Saint Mary's University, Canada.

29. Salamonson, Y., Everett, B., Koch, J., Andrew, S., \& Davidson, P. M. (2011). The impact of term-time paid work on academic performance in nursing students: A longitudinal study. International Journal of Nursing Studies, 49(5), 579-85.

30. Smith, S. M., Gorski, J. D., Hagmann, C. E., \& Oakley, J. S. (2002). The safety of adolescent workers. Professional Safety, 4(7), 29-33.

31. Tang. K.-T. (2002), Indigenous education in Taiwan: Rebuilding from the rubble. Taipei: Shita.

32. The Liberty Times (2010). Liberty Times: What stupid for university students to earn money while learning. Retrieved Dec. 12, 2012 from http://www.libertytimes.com.tw/2010/new/dec/2/today-life13.htm

33. Wang, C., \& Chen, S. (2013).Weighting the benefits of part-time employment in college: Perspectives from indigenous undergraduates. International Education Studies, 6(1), 104-110.

http://dx.doi.org/10.5539/ies.v6n1p104 